\title{
Results of Macitentan in Japanese Patients With Chronic Thromboembolic Pulmonary Hypertension \\ - A Prospective, Multicenter, Open-Label, Single-Arm, Phase 3 Study -
}

\author{
Satomi Sakurai, BSc; Yoshifumi Ukyo, PhD
}

\begin{abstract}
Background: Macitentan, an endothelin-receptor antagonist, is approved in Japan for the treatment of pulmonary arterial hypertension (PAH). This study evaluated the use of macitentan for chronic thromboembolic pulmonary hypertension (CTEPH) in Japanese patients.

Methods and Results: This open-label single-arm Phase 3 study evaluated the efficacy and safety of oral macitentan $10 \mathrm{mg}$ (once daily) in Japanese CTEPH patients. The study was prematurely discontinued due to the sponsor's decision to not develop macitentan $10 \mathrm{mg}$ further for the indication of CTEPH (unrelated to safety concerns). Of the 9 patients enrolled in the study, 4 completed 24 weeks of treatment. The mean ( \pm SD) ratio of pulmonary vascular resistance (PVR) at Week 16 to baseline was $71.9 \pm 34.3 \%$. The mean $\left( \pm\right.$ SD) decreases in PVR and the PVR index (PVRI) from baseline to Week 16 were $181.4 \pm 243.9 \mathrm{dyn} \cdot \mathrm{s} / \mathrm{cm}^{5}$ and $280.6 \pm 366.0 \mathrm{dyn} \cdot \mathrm{s} \cdot \mathrm{m}^{2} / \mathrm{cm}^{5}$, respectively. The mean $( \pm \mathrm{SD})$ increase in the 6 -min walk distance from baseline to Week 24 was $44.3 \pm 46.8 \mathrm{~m}$. All treatment-emergent adverse events (TEAEs) were mild or moderate in severity, except for 1 serious TEAE of angioplasty reported in $1 / 9$ patients that was severe in intensity.
\end{abstract}

Conclusions: Definite conclusions regarding the efficacy of macitentan $10 \mathrm{mg}$ in Japanese patients with CTEPH cannot be drawn because of premature study discontinuation. No safety concerns were observed, and the safety profile was consistent with previously reported studies in CTEPH and PAH patients.

Key Words: Chronic thromboembolic pulmonary hypertension; Endothelin receptor antagonists; Japan; Macitentan; Pulmonary arterial hypertension

C hronic thromboembolic pulmonary hypertension (CTEPH) is a rare and late complication of prior acute pulmonary embolism (PE) that has not resolved despite $>3$ months of treatment with anticoagulants. According to the clinical classification of pulmonary hypertension (PH), CTEPH is classified as Group 4, involving persistent organized thrombi in the proximal (main, lobar, and segmental) pulmonary arteries and microvasculopathy, which may lead to $\mathrm{PH}$ and increased pulmonary vascular resistance (PVR). ${ }^{1}$

The current standard treatment options for CTEPH include pulmonary endarterectomy (PEA), balloon pulmonary angioplasty (BPA), and pulmonary vasodilator therapy. ${ }^{2}$ PEA is the gold standard treatment for CTEPH worldwide, and has been demonstrated to be a curative option., 2,-5 Patients are evaluated for eligibility to undergo BPA if they are considered ineligible for PEA or have per- sistent PH following PEA. ${ }^{2}$ Pulmonary vasodilator therapy is considered if patients are ineligible for BPA. ${ }^{2}$ BPA and medical treatments (pulmonary vasodilator therapy) are more frequently used in Japan than in other countries because of the limited number of sites in Japan (only 5-10) performing PEA. ${ }^{2,6}$

The currently used treatment options are associated with their own challenges. PEA is a complex surgical procedure, and its success depends on the experience of the CTEPH medical team that decides an individual's operability, based on the lesion's location and hemodynamic parameters. In addition, PEA requires trained cardiac or thoracic surgeons, high-volume centers, special training, and postoperative intensive care. ${ }^{7,8}$ Conversely, postoperative lung injury is a common finding observed in patients undergoing BPA.,2,9

At present, the only pulmonary vasodilator approved in

Received April 1, 2021; revised manuscript received April 27, 2021; accepted May 10, 2021; J-STAGE Advance Publication released online June 9, 2021 Time for primary review: 12 days

Neuroscience, Pulmonary Hypertension, Cardiovascular \& Metabolism Clinical Development Department, Clinical Science Division (S.S.), Statistics and Decision Sciences Japan (Y.U.), Janssen Pharmaceutical K.K., Tokyo, Japan

Mailing address: Satomi Sakurai, BSc, Neuroscience, Pulmonary Hypertension, Cardiovascular \& Metabolism Clinical Development Department, Clinical Science Division, Janssen Pharmaceutical K.K., 5-2 Nishi-Kanda 3-chome, Chiyoda-ku, Tokyo 101-0065, Japan. E-mail: ssakura3@its.jnj.com

All rights are reserved to the Japanese Circulation Society. For permissions, please e-mail: cr@j-circ.or.jp

ISSN-2434-0790 
Japan for the treatment of CTEPH is riociguat (Adempas ${ }^{\circledR}$ : BAYER Yakuhin, Ltd, Osaka, Japan), a soluble guanylate cyclase (sGC) stimulator. ${ }^{2}$ This approval was based on the results of a multinational Phase 3 placebo-controlled study in which riociguat significantly improved exercise capacity (6-min walk distance [6MWD]) and PVR. ${ }^{10}$ Similarly, the results of a Phase 2 study of selexipag (UPTRAVI ${ }^{\circledR}$ : Nippon Shinyaku Co., Ltd., Kyoto, Japan), a selective prostacyclin receptor agonist, in Japanese patients with CTEPH showed improved pulmonary hemodynamics after 17 weeks of treatment; in the selexipag group, the mean $( \pm$ SD) decrease in PVR was $104 \pm 191 \mathrm{dyn} \cdot \mathrm{s} / \mathrm{cm}^{5}$ and the mean $( \pm \mathrm{SD})$ increase in 6MWD was $19 \pm 55 \mathrm{~m} .^{11}$ Nippon Shinyaku submitted an application in November 2020 for the use of selexipag in the treatment of CTEPH in Japan, with selexipag already approved for the treatment of pulmonary arterial hypertension (PAH). ${ }^{\mathbf{1 1}, \mathbf{1 2}}$

Macitentan, a dual endothelin receptor antagonist (ERA) with sustained receptor binding compared with other currently approved ERAs (bosentan and ambrisentan), has been shown to delay disease progression in patients with PAH.$^{13,14}$ Macitentan $\left(\right.$ Opsumit ${ }^{\circledR}$ : Janssen Pharmaceutical K.K., Tokyo, Japan) $10 \mathrm{mg}$ is approved for the treatment of PAH worldwide. ${ }^{15-21}$ In a multinational Phase 2 randomized placebo-controlled study (Macitentan in thE t $\underline{R}$ eatment of Inoperable chronic Thromboembolic pulmonary hypertension [MERIT-1]), macitentan $10 \mathrm{mg}$ significantly improved PVR, cardiac output (CO), cardiac index, and N-terminal pro B-type natriuretic peptide (NT-proBNP) in patients with inoperable CTEPH; however, that study did not include any Japanese patients. ${ }^{22}$ Thus, the present study was designed to assess the efficacy and safety of once daily administration of macitentan $10 \mathrm{mg}$ in Japanese patients with CTEPH. The study was prematurely discontinued due to the sponsor's decision to cease the further development of macitentan $10 \mathrm{mg}$ for CTEPH, and the sponsor voluntarily withdrew all health authority filings. The decision to discontinue the study was unrelated to any safety concerns. ${ }^{23}$

\section{Methods}

\section{Patient Selection}

Japanese CTEPH patients, aged between 18 and 89 years, were enrolled in the study if they were not eligible for PEA (technically non-operable, high risk, or other reasons why the investigator judged PEA not suitable at the time of informed consent), and/or patients with postoperative persistent or recurrent $\mathrm{PH}$ after PEA or BPA, as demonstrated by ventilation-perfusion (V/Q) scintigraphy (perfusion defects were observed in the segmental or sub-segmental branch regions with preserved ventilation) within 12 months before screening. Patients were diagnosed with CTEPH based on pulmonary angiography (PA) and/or chest contrast-enhanced computed tomography (CT); at facilities in which lung ventilation scintigrams were not available, a plain chest CT of the lungs was alternatively allowed to check for the absence of organic thrombosis.

Further, according to the right heart catheterization (RHC) performed within 8 weeks of screening, patients were included if they had a mean pulmonary artery pressure (mPAP) at rest of $\geq 25 \mathrm{mmHg}$, pulmonary arterial wedge pressure (PAWP) $\leq 15 \mathrm{mmHg}$ (or left ventricular end-diastolic pressure $\leq 13 \mathrm{mmHg}$ ), and PVR at rest $\geq 400 \mathrm{dyn} \cdot \mathrm{s} / \mathrm{cm}^{5}$. The $6 \mathrm{MWD}$ ranged from 150 to $450 \mathrm{~m}$ during the screening period, and patients were treated with anticoagulants, unfractionated heparin, or low molecular weight heparin for at least 90 days before the baseline RHC.

Patients were excluded from the study if they had: recurrent thromboembolism and were undergoing treatment with oral anticoagulants without showing treatment effect; symptomatic acute PE within 180 days prior to start of the macitentan; a total lung capacity $<60 \%$ of the predicted value or a forced expiratory volume in 1 second $\left(\mathrm{FEV}_{1}\right)$ $<70 \%$ of predicted or $\mathrm{FEV}_{1} /$ forced vital capacity (FVC) $<65 \%$; acute or chronic conditions (other than respiratory impairment) that could hamper treatment assessment; and undergone PEA within 180 days or BPA within 90 days before undergoing the baseline RHC. Patients who were World Health Organization functional class (WHO FC) I or II and received an sGC stimulator (riociguat), phosphodiesterase-5 inhibitors (PDE-5i; e.g., sildenafil, tadalafil, and vardenafil), or oral or inhaled prostanoids (e.g., beraprost sodium and iloprost) within 30 days prior to RHC at baseline were also excluded. Finally, patients initiating diuretics and/or calcium channel blockers (CCBs) or those with changes in the dosage of ongoing diuretics and/or CCBs within 1 week prior to baseline RHC were excluded.

The institutional review board at each study site approved the protocol. The study was conducted in accordance with the principles defined in the Declaration of Helsinki, International Council for Harmonization guidelines (Good Clinical Practices), and the local regulatory guidelines. Informed consent was obtained from all patients or their legally acceptable representatives prior to enrolment.

\section{Study Design}

This was a prospective multicenter open-label single-arm Phase 3 study to evaluate the efficacy and safety of macitentan in Japanese patients with CTEPH (ClinicalTrials.gov ID NCT03809650). The planned study design included a screening period (30 days), an efficacy evaluation period (24 weeks), an extension period (after the efficacy evaluation period until approval or discontinuation of macitentan development), and a safety follow-up period (up to 30 days after the end of the treatment [EOT]). Eligible patients received macitentan $10 \mathrm{mg}$ orally once daily until approval of macitentan in CTEPH was obtained in Japan or this study was discontinued.

\section{Efficacy Evaluations}

The primary efficacy endpoint was the ratio of resting PVR at Week 16 to that at baseline. Secondary efficacy endpoints included changes from baseline to Week 16 in resting PVR and the PVR index (PVRI), as well as changes from baseline to Week 24 in 6MWD, the Borg dyspnea index score following the 6MWD test, and WHO FC. The 6MWD test was performed to evaluate exercise capacity in patients. The Borg dyspnea index score was used to rate the severity of dyspnea on a scale from 0 ("nothing at all") to 10 ("very, very severe - maximal").

Other efficacy endpoints included: (1) changes from baseline to Week 16 in pulmonary hemodynamic parameters $(C O$, cardiac index, $\mathrm{mPAP}$, resting mean right atrium pressure [mRAP], PAWP, mixed venous oxygen saturation $\left[\mathrm{SvO}_{2}\right]$, and total peripheral resistance [TPR]); (2) changes in the 6MWD, Borg dyspnea index score, WHO FC, and NT-proBNP from baseline to each time point; and (3) time to first PH-related disease progression. 


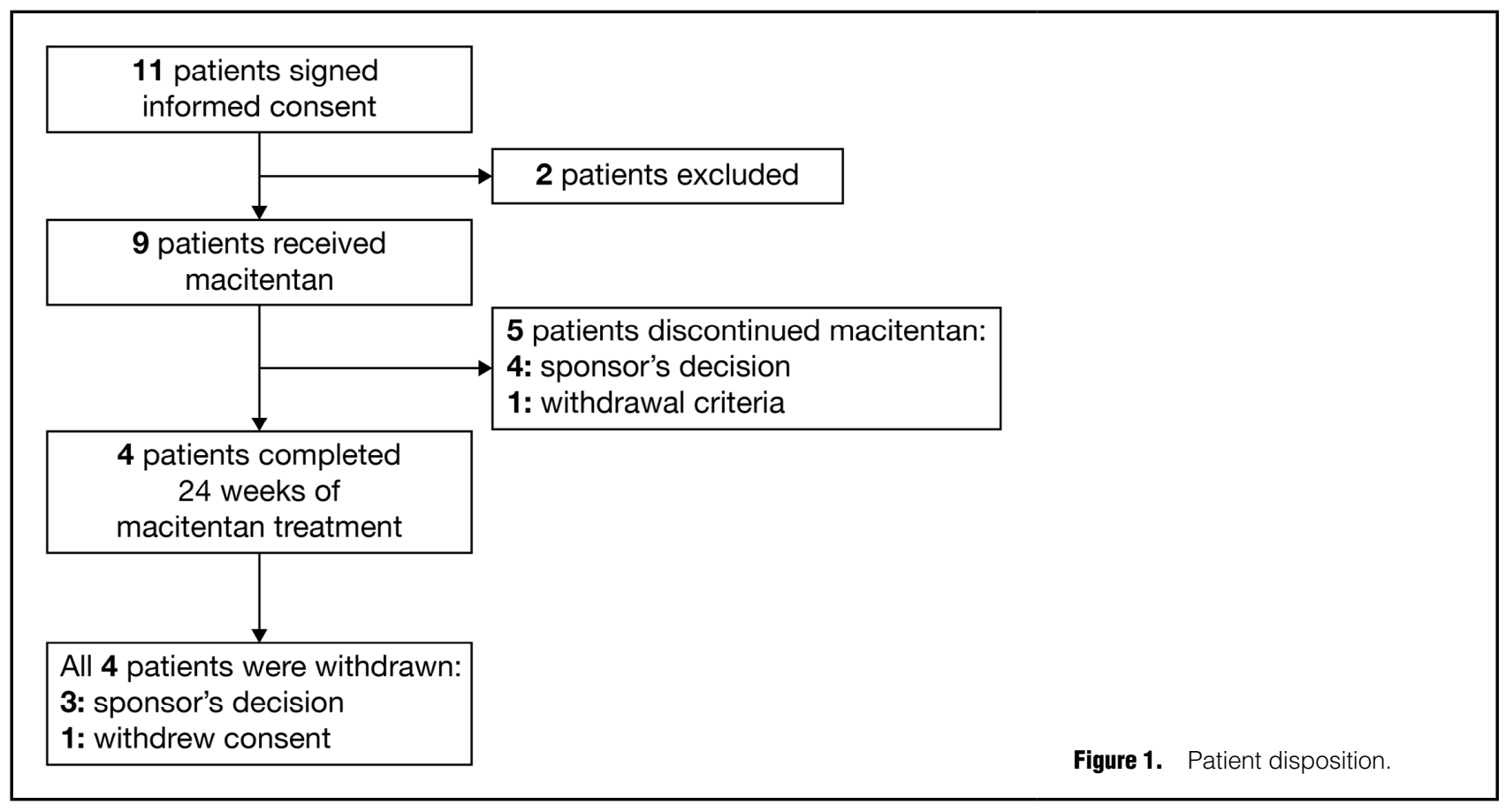

\section{Safety Evaluations}

Safety assessment was based on treatment-emergent adverse events (TEAEs), serious TEAEs, TEAEs leading to discontinuation of macitentan, TEAEs of special interest (decreased hemoglobin, anemia, edema, fluid retention, hepatic function disorder, and hypotension), clinical laboratory tests, and vital signs measurements.

\section{Statistical Methods}

Sample Size Determination There are no previous studies evaluating the efficacy of macitentan in Japanese patients, and there is no evidence indicating whether ethnic differences exist between Japanese and non-Japanese populations. The logarithm of PVR ratios was considered to follow normal distribution, and the means of PVR ratios (16 weeks/baseline) of 0.80 and 0.82 were assumed for patients treated with $\mathrm{PH}$ drug at baseline and patients with/without PH treatment at baseline, respectively, in the MERIT-1 study that investigated the efficacy of macitentan with non-Japanese CTEPH patients. The standard deviation (SD) of the logarithm of PVR ratios was determined as 0.3765 based on the MERIT- 1 study. ${ }^{22}$ Considering the imputation by the worst value in the MERIT-1 study with 0,1 , or 2 patients, a simulation study was performed to estimate the sample size by the non-parametric Wilcoxon's signed-rank test with a 2-sided significance level of 0.05. By anticipating that the treatment effect of riociguat as prior therapy (continued) was comparable to that of PDE-5i or prostanoid, 27 patients were required to ensure $70 \%$ power, taking the feasibility of the patients into account.

Analysis Sets Efficacy analysis was performed on the full analysis set (FAS), which included all patients who received at least 1 dose of macitentan and were evaluable for at least 1 efficacy assessment item. Safety analysis was performed on all patients who received at least 1 dose of macitentan and who were evaluable for safety after dosing.

Statistical Analyses In the original planned analysis, the primary efficacy endpoint (i.e., the ratio of PVR at Week
16 to that at baseline) was to be tested by the non-parametric Wilcoxon's signed-rank test with a 2-sided significance level of 0.05 . All other statistical tests for secondary endpoints had no formal statistical hypotheses. Thus, multiplicity was not considered.

Because the study was discontinued prematurely and the actual sample size was not considered to be sufficient to draw a robust conclusion, no formal statistical test was performed for the primary efficacy endpoint and other secondary endpoints, no imputation rules were applied for missing data, and no sensitivity analysis was performed. All efficacy endpoints were descriptively summarized. Geometric means, coefficients of variation (CV), and 95\% confidence intervals were estimated for the ratio of PVR at Week 16 to that at baseline as post hoc analyses. With regard to WHO FC, a categorical analysis was applied at each time point as a post hoc analysis.

All continuous and categorical safety variables were summarized descriptively. TEAEs were summarized using the Medical Dictionary for Regulatory Activities (MedDRA) version 22.1; system organ class (SOC) and preferred terms (PT) were used to summarize TEAEs. For each TEAE, the number and proportion of patients who experienced at least 1 occurrence of the given event were summarized.

Descriptive statistics included the number of patients, mean, SD, median, interquartile range (IQR), minimum, maximum, frequency counts, and proportions. Statistical analyses were performed using SAS version 9.4 (SAS Institute, Cary, NC, USA) and R was used for the preparation of graphs.

\section{Results}

In November 2019, the sponsor decided to cease the further development of macitentan $10 \mathrm{mg}$ for the treatment of inoperable CTEPH, and voluntarily withdrew the health authority filings that were still under review globally; hence, the present study was prematurely discontinued. 


\begin{tabular}{|c|c|}
\hline \multicolumn{2}{|l|}{ Sex } \\
\hline Female & 8 (88.9) \\
\hline Male & $1(11.1)$ \\
\hline \multicolumn{2}{|l|}{ Age (years) } \\
\hline Mean \pm SD & $69.0 \pm 9.2$ \\
\hline Median & 70.0 \\
\hline Minimum-maximum & $51-80$ \\
\hline Mean $\left( \pm\right.$ SD) BMI $\left(\mathrm{kg} / \mathrm{m}^{2}\right)$ & $21.8 \pm 3.9$ \\
\hline $\begin{array}{l}\text { Mean }( \pm S D) \text { time from CTEPH diagnosis } \\
\text { (years) }\end{array}$ & $1.9 \pm 4.7$ \\
\hline \multicolumn{2}{|l|}{ 6MWD (m) } \\
\hline Mean \pm SD & $341.8 \pm 84.9$ \\
\hline Minimum-maximum & $210-436$ \\
\hline \multicolumn{2}{|l|}{ WHO functional class } \\
\hline 1 & 0 \\
\hline II & $4(44.4)$ \\
\hline III & $5(55.6)$ \\
\hline IV & 0 \\
\hline \multicolumn{2}{|l|}{ PVR (dyn $\left.\cdot s / \mathrm{cm}^{5}\right)$} \\
\hline Mean \pm SD & $796.8 \pm 421.9$ \\
\hline Median & 671.0 \\
\hline IQR & $627.0-769.0$ \\
\hline Minimum-maximum & $404-1,859$ \\
\hline \multicolumn{2}{|l|}{ History of BPA/PEA } \\
\hline $\mathrm{BPA}^{\mathrm{A}}$ & $2(22.2)$ \\
\hline PEA $^{A}$ & $1(11.1)$ \\
\hline $\mathrm{PEA}+\mathrm{BPA}$ & $1(11.1)$ \\
\hline \multicolumn{2}{|l|}{ Concomitant use of PAH/CTEPH medication } \\
\hline Riociguat & $3(33.3)$ \\
\hline PDE-5i & 0 \\
\hline
\end{tabular}

Unless indicated otherwise, data are expressed as $n(\%)$. Ancluding 1 patient who underwent pulmonary endarterectomy (PEA) + balloon pulmonary angioplasty (BPA). 6MWD, 6-min walk distance; BMI, body mass index; CTEPH, chronic thromboembolic pulmonary hypertension; IQR, interquartile range; $\mathrm{PAH}$, pulmonary arterial hypertension; PDE-5i, phosphodiesterase type-5 inhibitors; PVR, pulmonary vascular resistance; WHO, World Health Organization.

\begin{tabular}{|c|c|}
\hline \multicolumn{2}{|c|}{ Ratio of PVR at Week 16 to baseline ${ }^{A}(\%)$} \\
\hline Mean \pm SD & $71.9 \pm 34.3$ \\
\hline Median & 66.0 \\
\hline IQR & $51.0,81.0$ \\
\hline Minimum-maximum & $21-138$ \\
\hline Geometric mean $(\mathrm{CV} \%)^{\mathrm{B}}$ & $64.1(58.1)$ \\
\hline $95 \% \mathrm{Cl}^{\mathrm{B}}$ & $42.3,97.0$ \\
\hline \multicolumn{2}{|l|}{ PVR (dyn.s/cm5) } \\
\hline \multicolumn{2}{|l|}{ Baseline } \\
\hline Mean \pm SD & $796.8 \pm 421.9$ \\
\hline Median & 671.0 \\
\hline IQR & $627.0,769.0$ \\
\hline \multicolumn{2}{|l|}{ Week 16} \\
\hline Mean \pm SD & $615.4 \pm 446.9$ \\
\hline Median & 441.0 \\
\hline IQR & $318.0,769.0$ \\
\hline \multicolumn{2}{|c|}{ Change from baseline at Week 16} \\
\hline Mean \pm SD & $-181.4 \pm 243.9$ \\
\hline Median & -230.0 \\
\hline IQR & $-313.0,-147.0$ \\
\hline \multicolumn{2}{|l|}{ PVRI (dyn.s $\left.\cdot \mathrm{m}^{2} / \mathrm{cm}^{5}\right)$} \\
\hline \multicolumn{2}{|l|}{ Baseline } \\
\hline Mean \pm SD & $1,155.2 \pm 532.2$ \\
\hline Median & 952.4 \\
\hline IQR & $900.0,1,111.1$ \\
\hline \multicolumn{2}{|l|}{ Week 16} \\
\hline Mean \pm SD & $874.6 \pm 628.1$ \\
\hline Median & 577.8 \\
\hline IQR & $471.8,1,173.3$ \\
\hline \multicolumn{2}{|c|}{ Change from baseline at Week 16} \\
\hline Mean \pm SD & $-280.6 \pm 366.0$ \\
\hline Median & -322.2 \\
\hline IQR & $-523.1,-187.2$ \\
\hline
\end{tabular}

For PVR and the PVR index (PVRI), data are expressed as mean \pm SD. AThe ratio was calculated as (PVR at Week 16/PVR at baseline) $\times 100$. ${ }^{\mathrm{B} T}$ The geometric mean, coefficients of variation (CV), and 95\% confidence intervals $(\mathrm{Cl})$ were estimated for the ratio of PVR at Week 16 to that at baseline as a post hoc analysis. IQR, interquartile range; PVR, pulmonary vascular resistance.
This decision was not attributed to any safety concerns. ${ }^{23}$

\section{Study Population}

The study was conducted across 32 sites in Japan from 13 May 2019 to 30 March 2020. Of the 11 patients screened, $9(81.8 \%)$ were enrolled and received macitentan. Five patients were prematurely withdrawn from the study before Week 24 because of the sponsor's decision to prematurely discontinue the study $(n=4)$ and meeting the withdrawal criterion of being unable to complete the medication diary $(n=1)$. Four patients completed 24 weeks of macitentan treatment, of whom 3 withdrew because of the sponsor's decision and 1 withdrew consent (Figure 1).

The safety and efficacy analysis sets included data from all 9 patients enrolled in the study. Overall, there was a higher proportion of women (8/9 patients; $88.9 \%$ ) than men (1/9 patients; $11.1 \%$ ). The median age was 70.0 years (range $51-80$ years), with most patients being $\geq 65$ years of age $(\mathrm{n}=7 / 9 ; 77.8 \%)$. At baseline, patients were either WHO FC II (4/9 patients; $44.4 \%$ ) or III (5/9 patients; $55.6 \%$ ), and 2 of 9 patients $(22.2 \%)$ had a history of BPA, 1 of whom also had a history of PEA. At baseline, 3 of 9 patients $(33.3 \%)$ were receiving riociguat for CTEPH. The detailed demographic and baseline patient characteristics are provided in Table 1.

Three patients were reported as having major protocol deviations in the study. One patient had a change in oxygen condition of RHC from "yes" at screening to "no" at Week 16. One patient had the following deviations: discontinuation of CCBs, initiation and interruption of diuretics, and the 6MWD and Borg dyspnea index score at EOT being performed outside the window period. One patient had a reduction in the dose of CCBs.

The mean $( \pm \mathrm{SD})$ percentage of macitentan compliance was $99.2 \pm 2.2 \%$. The median duration of exposure to macitentan was 22.6 weeks (range 9-34 weeks). 


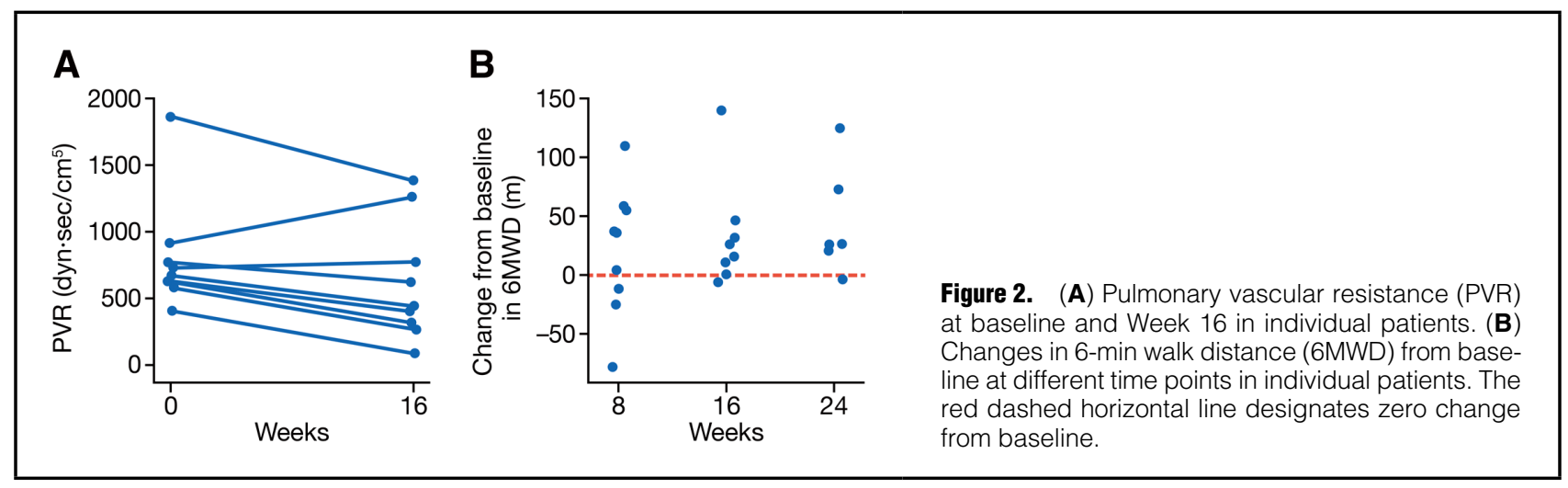

\begin{tabular}{|c|c|c|c|}
\hline & $\begin{array}{c}\text { Baseline } \\
(n=9)\end{array}$ & $\begin{array}{c}\text { Week } 24 \\
(n=6)^{B}\end{array}$ & $\begin{array}{c}\text { Change } \\
(n=6)\end{array}$ \\
\hline 6MWD (m) & $341.8 \pm 84.9$ & $389.3 \pm 111.9$ & $44.3 \pm 46.8$ \\
\hline Borg dyspnea index & $5.4 \pm 2.2$ & $5.5 \pm 2.3$ & $0.2 \pm 1.9$ \\
\hline \multicolumn{4}{|l|}{ WHO functional class ${ }^{A}$} \\
\hline No. patients & 9 & 5 & - \\
\hline I & 0 & 0 & - \\
\hline II & $4(44.4 \%)$ & $3(60.0 \%)$ & - \\
\hline III & $5(55.6 \%)$ & $2(40.0 \%)$ & - \\
\hline IV & 0 & 0 & - \\
\hline
\end{tabular}

Unless indicated otherwise, data are expressed as the mean \pm SD or $n(\%)$. ${ }^{A}$ Categorical analysis of World Health Organization (WHO) functional class was performed as a post hoc analysis. BWeek 24 (141-252 days), data from 6 patients who underwent both assessments during this period were used for the calculation. 6MWD, 6-minute walk distance.

\section{Efficacy Findings}

Primary Efficacy Endpoint The mean $( \pm \mathrm{SD})$ ratio of PVR at Week 16 to that at baseline was $71.9 \pm 34.3 \%$ in the FAS $(n=9$; Table 2). There was a $28.1 \%$ reduction in PVR at Week 16 compared with baseline. The geometric mean (CV) ratio of PVR at Week 16 to that at baseline was $64.1 \pm 58.1 \%$. No missing values were observed for the primary efficacy endpoint.

Secondary Efficacy Endpoints There was a mean $( \pm$ SD $)$ decrease in PVR and PVRI from baseline to Week 16 of $181.4 \pm 243.9 \mathrm{dyn} \cdot \mathrm{s} / \mathrm{cm}^{5}$ and $280.6 \pm 366.0 \mathrm{dyn} \cdot \mathrm{s} \cdot \mathrm{m}^{2} / \mathrm{cm}^{5}$, respectively ( $\mathrm{n}=9$; Table 2). Individual plots of PVR showed that 7 of 9 patients had a decrease in PVR from baseline to Week 16 (Figure 2). Two patients had an increase in PVR from baseline to Week 16; 1 of these patients had a history of BPA at baseline. Among these 2 patients, the patient who had no history of BPA at baseline had a higher increase in PVR from baseline to Week 16 $\left(347.3 \mathrm{dyn} \cdot \mathrm{s} / \mathrm{cm}^{5}\right)$ than the patient with a history of BPA at baseline $\left(43.9 \mathrm{dyn} \cdot \mathrm{s} / \mathrm{cm}^{5}\right)$.

At Week 24 , the mean $( \pm \mathrm{SD}) 6 \mathrm{MWD}$ increased from a baseline value of $341.8 \pm 84.9 \mathrm{~m}$ by $44.3 \pm 46.8 \mathrm{~m}$. The Borg dyspnea index score showed no clinically meaningful change from baseline to Week 24. At baseline, the mean $( \pm \mathrm{SD})$ Borg dyspnea index score was $5.4 \pm 2.2$, compared with $5.5 \pm 2.3$ at Week 24 (Table 3). The results of the 6MWD and Borg dyspnea index score at Week 24 are presented only for the 6 patients who underwent these assessments during this period. One of 9 patients (11.1\%) showed an improvement from WHO FC III to II at Week 8 , whereas all other patients were stable during the study; WHO FC results at Week 24 are presented for only the 5 patients who underwent this assessment during this period.

\section{Other Efficacy Endpoints}

At Week 16 , mean ( \pm SD) increases (i.e., improvements) of $0.8 \pm 1.5 \mathrm{~L} / \mathrm{min}, 0.6 \pm 0.9 \mathrm{~L} / \mathrm{min} / \mathrm{m}^{2}, 0.7 \pm 2.4 \mathrm{mmHg}$, and $0.3 \pm 11.8 \%$ from baseline were observed for $\mathrm{CO}$, cardiac index, PAWP, and $\mathrm{SvO}_{2}$, respectively. At Week 16, mean $( \pm$ SD) decreases (i.e., improvements) of $4.0 \pm 7.4 \mathrm{mmHg}$, $0.1 \pm 2.7 \mathrm{mmHg}, 180.1 \pm 251.1 \mathrm{dyn} \cdot \mathrm{s} / \mathrm{cm}^{5}$, and $55.5 \pm 86.9 \mathrm{pg} / \mathrm{mL}$ from baseline were observed for mPAP, mRAP, TPR, and NT-proBNP, respectively (Table 4).

Individual plots of changes from baseline to Week 24 in the 6MWD showed that 6MWD increased in most patients from baseline to Week 24 (Figure 2). The mean $( \pm \mathrm{SD})$ increases in 6MWD from baseline to Weeks 8, 16, and 24 were $20.7 \pm 55.1,33.4 \pm 46.3$, and $44.3 \pm 46.8 \mathrm{~m}$, respectively. No clinically meaningful changes were observed in the Borg dyspnea index score from baseline over time until the end of the study. The WHO FC for 8 of 9 patients $(88.9 \%)$ did not change throughout the study period; 1 patient (11.1\%) showed an improvement in WHO FC from III to II. A decrease in mean $( \pm$ SD) NT-proBNP concentrations was observed from Week 4 to Week 20 compared to baseline, ranging from $12.9 \pm 178.2$ to $164.1 \pm 498.8 \mathrm{pg} / \mathrm{mL}$. At Week 24 , there was a mean $( \pm \mathrm{SD})$ increase in NT-proBNP concentrations of $22.2 \pm 182.6 \mathrm{pg} / \mathrm{mL}$ compared with base- 


\begin{tabular}{|c|c|c|c|}
\hline & Mean \pm SD & Median & IQR \\
\hline \multicolumn{4}{|l|}{ Cardiac output (L/min) } \\
\hline Baseline & $3.1 \pm 0.9$ & 3.2 & $2.6,3.8$ \\
\hline Week 16 & $4.0 \pm 2.1$ & 3.4 & $2.4,4.7$ \\
\hline Change from baseline at Week 16 & $0.8 \pm 1.5$ & 0.2 & $0.1,1.5$ \\
\hline \multicolumn{4}{|l|}{ Cardiac index (L/min/m²) } \\
\hline Baseline & $2.1 \pm 0.5$ & 2.1 & $1.8,2.4$ \\
\hline Week 16 & $2.7 \pm 1.3$ & 2.3 & $1.5,3.6$ \\
\hline Change from baseline at Week 16 & $0.6 \pm 0.9$ & 0.1 & $0.1,1.1$ \\
\hline \multicolumn{4}{|l|}{ mPAP $(\mathrm{mmHg})$} \\
\hline Baseline & $35.8 \pm 6.7$ & 35.0 & $30.0,41.0$ \\
\hline Week 16 & $31.8 \pm 8.7$ & 33.0 & $26.0,37.0$ \\
\hline Change from baseline at Week 16 & $-4.0 \pm 7.4$ & -6.0 & $-7.0,-4.0$ \\
\hline \multicolumn{4}{|l|}{ mRAP (mmHg) } \\
\hline Baseline & $4.7 \pm 2.7$ & 5.0 & $3.0,7.0$ \\
\hline Week 16 & $4.6 \pm 2.6$ & 5.0 & $3.0,6.0$ \\
\hline Change from baseline at Week 16 & $-0.1 \pm 2.7$ & 0.0 & $-2.0,1.0$ \\
\hline \multicolumn{4}{|l|}{ PAWP (mmHg) } \\
\hline Baseline & $7.6 \pm 2.8$ & 8.0 & $4.0,10.0$ \\
\hline Week 16 & $8.2 \pm 2.9$ & 9.0 & $8.0,10.0$ \\
\hline Change from baseline at Week 16 & $0.7 \pm 2.4$ & 1.0 & $-1.0,2.0$ \\
\hline \multicolumn{4}{|l|}{$\mathrm{SvO}_{2}(\%)$} \\
\hline Baseline & $65.9 \pm 7.3$ & 67.0 & $58.2,70.4$ \\
\hline Week 16 & $66.2 \pm 13.3$ & 65.6 & $57.0,69.0$ \\
\hline Change from baseline at Week 16 & $0.3 \pm 11.8$ & -0.2 & $-7.8,1.6$ \\
\hline \multicolumn{4}{|l|}{$\operatorname{TPR}\left(\right.$ dyn $\left.\cdot \mathbf{s} \cdot \mathrm{m}^{2} / \mathrm{cm}^{5}\right)$} \\
\hline Baseline & $988.2 \pm 415.5$ & 869.6 & $819.1,1,043.5$ \\
\hline Week 16 & $808.1 \pm 495.4$ & 610.2 & $456.8,1,048.0$ \\
\hline Change from baseline at Week 16 & $-180.1 \pm 251.1$ & -254.4 & $-315.2,-213.9$ \\
\hline \multicolumn{4}{|l|}{ NT-proBNP $(p g / m L)^{A}$} \\
\hline Baseline & $746.4 \pm 1,447.1$ & 226.0 & $129.0,345.0$ \\
\hline Week 16 & $213.8 \pm 223.6$ & 146.5 & $45.0,308.0$ \\
\hline Change from baseline at Week 16 & $-55.5 \pm 86.9$ & -78.0 & $-105.5,-31.0$ \\
\hline
\end{tabular}

AThe number of patients analyzed was 9,8 , and 8 at baseline, Week 16, and for the change from baseline at Week 16 , respectively. IQR, interquartile range; $\mathrm{mPAP}$, mean pulmonary arterial pressure; mRAP, mean right atrial pressure; NT-proBNP, N-terminal pro B-type natriuretic peptide; PAWP, pulmonary arterial wedge pressure; $\mathrm{SvO}_{2}$, mixed venous oxygen saturation; TPR, total pulmonary resistance.

line. No patient reported PH-related disease progression prior to study discontinuation; hence, all patients were censored.

\section{Safety Findings}

All patients experienced at least 1 TEAE, with the most frequently reported TEAEs (in $\geq 20 \%$ patients) being nasopharyngitis and angioplasty (4 of 9 patients [44.4\%] each) and fatigue ( 2 of 9 patients; $22.2 \%$ ). All serious TEAEs reported were that of angioplasty (hospitalization for BPA), which occurred in 4 of 9 patients $(44.4 \%)$ on the same day or at later days after macitentan discontinuation; none was assessed as being related to macitentan. Angioplasty was performed in these 4 patients because further therapeutic actions for CTEPH were judged to be required. All TEAEs were mild or moderate in severity, except a serious TEAE of angioplasty in 1 patient that was severe. The TEAEs of special interest were reported in 4 of 9 patients $(44.4 \%)$ : mild joint swelling $(n=1)$; mild anemia and mildly abnormal liver function test $(\mathrm{n}=1)$; mild hypo- tension and moderate edema $(\mathrm{n}=1)$; and a mild decrease in blood pressure (BP; $n=1)$. All of these, except the joint swelling and the abnormal liver function test, were assessed as being related to macitentan. Overall, TEAEs that were considered related to macitentan were reported in 3 of 9 patients $(33.3 \%)$ : nasal congestion and anemia $(n=1)$; fatigue, hypotension, and edema $(\mathrm{n}=1)$; and decrease in $\mathrm{BP}$ $(n=1)$. No deaths or TEAEs leading to macitentan interruption or discontinuation were reported during the study (Table 5).

Overall, the mean changes from baseline in laboratory values were not clinically meaningful. A marked abnormality of a decrease in hemoglobin from baseline $(\geq 20 \mathrm{~g} / \mathrm{L}$ and $<50 \mathrm{~g} / \mathrm{L})$ was reported in 1 patient $(11.1 \%)$. This patient was reported with 2 mild TEAEs of anemia on Days 60 and 101, of which the first event resolved, whereas the second event was reported as not resolved at the time of reporting of results.

No clinically meaningful trends were observed for any of the vital signs measurements. 


\begin{tabular}{|lc|}
\hline $\begin{array}{l}\text { Table 5. Most Frequent Adverse Events and Abnormal Laboratory Results in Patients Administered } \\
\text { Macitentan } 10 \mathbf{m g}(\mathbf{n}=9)\end{array}$ & $9(100)$ \\
Patients with $\geq 1$ TEAE & $4(44.4)$ \\
Nasopharyngitis & $4(44.4)$ \\
Angioplasty & $2(22.2)$ \\
Fatigue & $4(44.4)$ \\
Patients with serious TEAEB & 0 \\
Patients with TEAEs leading to discontinuation of study treatment & \\
Patients with special interest TEAE and abnormal laboratory results & $1(11.1)$ \\
Blood pressure decrease & $1(11.1)$ \\
Abnormal liver function test & $1(11.1)$ \\
Anemia & $1(11.1)$ \\
Edema & $1(11.1)$ \\
Joint swelling & $1(11.1)$ \\
Hypotension & $1(11.1)$ \\
Hemoglobin decrease from baseline $\geq 20$ and $<50 \mathrm{~g} / \mathrm{L}$ & \\
\hline
\end{tabular}

Data are given as $n(\%)$. ${ }^{A}$ Treatment-emergent adverse events (TEAEs) with $\geq 2$ patients reported are listed. ${ }^{\mathrm{B}} \mathrm{All}$ serious TEAEs reported were angioplasty (hospitalization for balloon pulmonary angioplasty), performed on the same day or later than the date of macitentan discontinuation.

\section{Discussion}

Because a global Phase 2 clinical study (MERIT-1) in CTEPH patients showed favorable results with macitentan $10 \mathrm{mg}$, 22 the present study was conducted to assess the efficacy and safety of macitentan $10 \mathrm{mg}$ in Japanese patients with CTEPH who were not indicated for PEA and/or patients who had postoperative persistent or recurrent $\mathrm{PH}$ after PEA and/or BPA. There was a clinical interest to assess the efficacy and safety of macitentan in Japanese patients with CTEPH compared with non-Japanese patients, and this study was expected to show supporting evidence for the use of macitentan $10 \mathrm{mg}$ in Japanese patients with CTEPH.

Although the results of the MERIT-1 study had been used to apply for approval to the European Medicines Agency and US Food and Drug Administration in November 2019, the sponsor decided to voluntarily withdraw all health authority filings for macitentan $10 \mathrm{mg}$ for the treatment of patients with inoperable CTEPH. Because of this decision, the present study was prematurely discontinued. As a result, only 9 patients were enrolled and received macitentan $10 \mathrm{mg}$, of whom 4 completed 24 weeks of macitentan treatment.

Compared with CTEPH patients from 6 European countries, ${ }^{24}$ the present study had a higher proportion of women $(88.9 \%$ vs. $60.5 \%)$ and higher baseline mean 6MWD values $(341.8 \mathrm{~m}$ vs. $298.0 \mathrm{~m})$. Although the actual sample size of the present study was small, other demographic and clinical characteristics were generally consistent with the characteristics of the wider inoperable CTEPH population.

As in PAH, endothelin-mediated vascular remodeling has been demonstrated in animal models of CTEPH, and increased endothelin levels and endothelin $\mathrm{B}$ receptor expression have been observed in CTEPH patients. ${ }^{25,26}$ For these reasons, ERA like macitentan appears to be a potential treatment option for CTEPH. A reduction in PVR by therapeutic intervention is considered as a factor that could lead to improvements in mortality in CTEPH patients. ${ }^{27-29}$ In the present study, the mean ( \pm SD) decrease in PVR at Week 16 was $181.4 \pm 243.9 \mathrm{dyn} \cdot \mathrm{s} / \mathrm{cm}^{5}$, similar to that observed in the MERIT-1 study $\left(206 \pm 450.4 \mathrm{dyn} \cdot \mathrm{s} / \mathrm{cm}^{5}\right)$ and other previous studies of various treatments available for CTEPH. ${ }^{10,11,30}$ Future studies are expected to clarify the relationship between hemodynamic values and long-term outcomes in CTEPH patients.

Further, after 24 weeks of macitentan treatment, there was an improvement in the $6 \mathrm{MWD}$, with a mean $( \pm \mathrm{SD})$ increase of $44.3 \pm 46.8 \mathrm{~m}$, consistent with the results observed in the MERIT-1 study $(35.0 \pm 52.5 \mathrm{~m})$. Overall, the efficacy results were numerically similar to the results of the MERIT-1 study;22 however, caution is required when interpreting the results of the present study because of the small sample size.

Based on the sample size of 9 patients and the median treatment duration of 22.6 weeks (range 9-34 weeks), the safety profile of macitentan $10 \mathrm{mg}$ was consistent with previously reported studies in patients with $\mathrm{CTEPH}^{22}$ and PAH. ${ }^{14}$ The combination of macitentan and riociguat was also found to be safe in a real-world study with inoperable and residual CTEPH patients. ${ }^{31}$ Although TEAEs of hemoptysis and pulmonary hemorrhage, including cases with fatal outcome, have been observed in patients with CTEPH or PAH treated with riociguat, ${ }^{10,32,33}$ no such TEAEs were reported in the present study.

The most frequently reported TEAEs in this study were nasopharyngitis, angioplasty, and fatigue; TEAEs of special interest included joint swelling, anemia, abnormal liver function tests, hypotension, edema, and decreases in BP. The TEAEs observed in this study were consistent with TEAEs reported for treatment with other ERAs (edema, anemia and/or decreased hemoglobin, and abnormal liver function tests). ${ }^{30,34,35}$ All TEAEs were mild or moderate in severity, and no deaths or TEAEs leading to macitentan interruption or discontinuation were reported during the study.

This study has 2 major limitations. The first is the small sample size compared with the planned sample size of 27 patients. Nine treated patients is not sufficient to support a definitive conclusion. The other limitation of this study is the design; this study had a single arm, with no control. Recently, the results of a Phase 2 study in Japanese CTEPH patients treated with selexipag have been published. ${ }^{11}$ That Phase 2 study was a randomized doubleblind placebo-controlled trial (unlike the present study) 
and should be taken into account while evaluating the results of the present study to understand the treatment effect with macitentan.

Because the present study was prematurely discontinued, no definite conclusions can be drawn. Thus, future studies are required to assess the efficacy and safety of macitentan in Japanese CTEPH patients. Recently, a global study has been started to evaluate the efficacy of macitentan $75 \mathrm{mg}$ in patients with CTEPH (the Macitentan in inoper $\underline{A}$ ble or persistent/reCurrent chronI $\underline{\text { Th }}$ ThromboEmbolic Pulmonary Hypertension [MACiTEPH] study), ${ }^{36}$ which includes Japanese patients. This study will potentially help answer further questions regarding the use of macitentan in Japanese CTEPH patients.

\section{Conclusions}

In Japanese patients with CTEPH, a definite conclusion could not be drawn about the efficacy of macitentan $10 \mathrm{mg}$ due to premature study discontinuation and the small number of patients evaluated. Although no safety concerns were observed in the present study, future studies are warranted to assess the efficacy and safety of macitentan in CTEPH Japanese patients.

\section{Acknowledgments}

The authors thank Yoshinari Yokoyama for contributing to this study. Writing support was provided by Vivek Rane, Vasudha Chachra, and Kiran Chawla from Kinapse (a Syneos Health Company). Additional editorial support was provided by Akashi Otaki and Toshiyuki Sekiguchi (Janssen Pharmaceutical K.K., Japan). The authors also thank the study participants and their families, without whom this study would not have been accomplished, and the investigational site and their staff for their contributions to this study.

\section{Sources of Funding}

This study was funded by Janssen Pharmaceutical K.K. (Tokyo, Japan) and Actelion Pharmaceuticals Japan Ltd (Tokyo, Japan).

\section{Authors' Contribution}

The authors contributed to the interpretation of data as well as critical revision of the manuscript for important intellectual content. S.S. contributed in the concept and study design. Y.U. contributed for the statistical analysis. The authors made the final decision about where to publish these data and approved submission to this journal. The authors agreed to be accountable for all aspects of the work in ensuring that questions related to the accuracy or integrity of any part of the work are appropriately investigated and resolved.

\section{Disclosures}

S.S. and Y.U. are employees of Janssen Pharmaceutical K.K. (Tokyo, Japan).

\section{IRB Information}

The study protocol was approved by the Institutional Review Board (IRB) of Nagasaki University Hospital (Reference no. 00009218) and by the IRBs of each of the 30 other participating study sites.

\section{Data Availability}

Janssen pharmaceutical companies of Johnson\&Johnson have an agreement with the Yale Open Data Access (YODA) Project (https:// www.janssen.com/clinical-trials/transparency) to serve as the independent review panel for the evaluation of requests for clinical study reports and participant-level data from investigators and physicians for scientific research that will advance medical knowledge and public health. For information on this process, please visit the YODA Project site (https://yoda.yale.edu/). Procedures to guide external investigator access to clinical trial data are available at https://yoda. yale.edu/sites/default/files/files/YODA $\% 20$ Project $\% 20$ Data $\% 20$
Release $\% 20$ Procedures $\% 20$ February\%202019.pdf.

\section{References}

1. Simonneau G, Torbicki A, Dorfmüller P, Kim N. The pathophysiology of chronic thromboembolic pulmonary hypertension. Eur Respir Rev 2017; 26: 160112.

2. Fukuda K, Date H, Doi S, Fukumoto Y, Fukushima N, Hatano $\mathrm{M}$, et al; on behalf of the Japanese Circulation Society and the Japanese Pulmonary Circulation and Pulmonary Hypertension Society Joint Working Group. Guidelines for the treatment of pulmonary hypertension (JCS 2017/JPCPHS 2017). Circ J 2019; 83: $842-945$.

3. Madani MM, Auger WR, Pretorius V, Sakakibara N, Kerr KM, Kim NH, et al. Pulmonary endarterectomy: Recent changes in a single institution's experience of more than 2,700 patients. Ann Thorac Surg 2012; 94: 97-103.

4. Mayer E, Jenkins D, Lindner J, D’Armini A, Kloek J, Meyns B, et al. Surgical management and outcome of patients with chronic thromboembolic pulmonary hypertension: Results from an international prospective registry. J Thorac Cardiovasc Surg 2011; 141: $702-710$.

5. Kim NH. Assessment of operability in chronic thromboembolic pulmonary hypertension. Proc Am Thorac Soc 2006; 3: 584-588.

6. Japanese Pulmonary Circulation and Pulmonary Hypertension Society. Chronic thromboembolic pulmonary hypertension (CTEPH) clinical practice guidelines [in Japanese]. Japan Pulmonary Hypertension and Pulmonary Circulation Society, 2018.

7. Jenkins D, Madani M, Fadel E, D'Armini AM, Mayer E. Pulmonary endarterectomy in the management of chronic thromboembolic pulmonary hypertension. Eur Respir Rev 2017; 26: 160111.

8. Delcroix M, Torbicki A, Gopalan D, Sitbon O, Klok FA, Lang I, et al. ERS statement on chronic thromboembolic pulmonary hypertension. Eur Respir J, 02828-2020.

9. Zoppellaro G, Badawy MR, Squizzato A, Denas G, Tarantini G, Pengo V. Balloon pulmonary angioplasty in patients with chronic thromboembolic pulmonary hypertension: A systematic review and meta-analysis. Circ J 2019; 83: 1660-1667.

10. Ghofrani HA, D'Armini AM, Grimminger F, Hoeper MM, Jansa P, Kim NH, et al. Riociguat for the treatment of chronic thromboembolic pulmonary hypertension. N Engl J Med 2013; 369: $319-329$.

11. Tanabe N, Fukuda K, Matsubara H, Nakanishi N, Tahara N, Ikeda $\mathrm{S}$, et al. Selexipag for chronic thromboembolic pulmonary hypertension in Japanese patients: A double-blind, randomized, placebo-controlled, multicenter Phase II study. Circ J 2020; 84: $1866-1874$.

12. Nippon Shinyaku Co. Ltd. Nippon Shinyaku submitted additional application of Uptravi ${ }^{\circledR}$ for "chronic thromboembolic pulmonary hypertension (CTEPH)" [News Release]. 2020. https://www.nippon-shinyaku.co.jp/file/download.php?file_ id=3393 (accessed December 2, 2020).

13. Gatfield J, Mueller Grandjean C, Sasse T, Clozel M, Nayler O. Slow receptor dissociation kinetics differentiate macitentan from other endothelin receptor antagonists in pulmonary arterial smooth muscle cells. PLoS One 2012; 7: e47662.

14. Pulido T, Adzerikho I, Channick RN, Delcroix M, Galiè N, Ghofrani HA, et al. Macitentan and morbidity and mortality in pulmonary arterial hypertension. N Engl J Med 2013; 369: 809-818.

15. Patel T, McKeage K. Macitentan: First global approval. Drugs 2014; 74: $127-133$.

16. European Medicines Agency. Opsumit (macitentan). 2013. https://www.ema.europa.eu/en/medicines/human/EPAR/opsumit (accessed November 24, 2020).

17. Product information for AusPAR Opsumit (macitentan) $10 \mathrm{mg}$ film coated tablet. 2014. https://www.tga.gov.au/sites/default/ files/auspar-macitentan-140428-pi.pdf (accessed November 24, 2020).

18. Swissmedic. Opsumit, film coated tablets (macitentan). 2014. https://www.swissmedic.ch/swissmedic/en/home/ humanarzneimittel/authorisations/new-medicines/opsumit-filmtabletten--macitentanum-.html (accessed November 24, 2020).

19. Pharmaceutical and Medical Device Agency, Japan. Annual report FY 2014 (April 2014-March 2015). https://www.pmda. go.jp/files/000208305.pdf\#page=167 (accessed November 24, 2020).

20. Sidharta PN, Štěpánová R, Globig S, Ulč I, Csonka D. Relative bioavailability of a pediatric dispersible tablet and adult film- 
coated tablet of macitentan in healthy volunteers. Pharmacol Res Perspect 2020; 8: e00580.

21. Jansa P, Pulido T. Macitentan in pulmonary arterial hypertension: A focus on combination therapy in the SERAPHIN trial. Am J Cardiovasc Drugs 2018; 18: 1-11.

22. Ghofrani HA, Simonneau G, D'Armini AM, Fedullo P, Howard LS, Jaïs X, et al. Macitentan for the treatment of inoperable chronic thromboembolic pulmonary hypertension (MERIT-1): Results from the multicentre, phase 2, randomised, double-blind, placebo-controlled study. Lancet Respir Med 2017; 5: 785-794.

23. Actelion, A Janssen Pharmaceutical Company of Johnson and Johnson. Actelion withdraws regulatory filings to extend the indication of OPSUMIT ${ }^{\circledR}$ (macitentan $10 \mathrm{mg}$ ) in CTEPH [Press Release]. 2019. https://johnsonandjohnson.gcs-web.com/staticfiles/fa581367-13b5-47ac-91df-bb6bf635131e (accessed December 11, 2020)

24. Schweikert B, Pittrow D, Vizza CD, Pepke-Zaba J, Hoeper MM, Gabriel A, et al. Demographics, clinical characteristics, health resource utilization and cost of chronic thromboembolic pulmonary hypertension patients: Retrospective results from six European countries. BMC Health Serv Res 2014; 14: 246.

25. Bauer M, Wilkens H, Langer F, Schneider S, Lausberg H, Schäfers HJ. Selective upregulation of endothelin B receptor gene expression in severe pulmonary hypertension. Circulation 2002; 105: 1034-1036.

26. Kim H, Yung GL, Marsh JJ, Konopka RG, Pedersen CA, Chiles $\mathrm{PG}$, et al. Pulmonary vascular remodeling distal to pulmonary artery ligation is accompanied by upregulation of endothelin receptors and nitric oxide synthase. Exp Lung Res 2000; 26: $287-301$

27. Skoro-Sajer N, Bonderman D, Wiesbauer F, Harja E, Jakowitsch J, Klepetko W, et al. Treprostinil for severe inoperable chronic thromboembolic pulmonary hypertension. J Thromb Haemost 2007; 5: 483-489.

28. Nishimura R, Tanabe N, Sugiura T, Shigeta A, Jujo T, Sekine A, et al. Improved survival in medically treated chronic thromboembolic pulmonary hypertension. Circ J 2013; 77: 2110-2117.

29. Dartevelle P, Fadel E, Mussot S, Chapelier A, Hervé P, de Perrot $\mathrm{M}$, et al. Chronic thromboembolic pulmonary hypertension. Eur Respir J 2004; 23: 637-648.

30. Jais X, D'Armini AM, Jansa P, Torbicki A, Delcroix M, Ghofrani $\mathrm{HA}$, et al. Bosentan for treatment of inoperable chronic thromboembolic pulmonary hypertension: BENEFiT (Bosentan Effects in iNopErable Forms of chronIc Thromboembolic pulmonary hypertension), a randomized, placebo-controlled trial. J Am Coll Cardiol 2008; 52: 2127-2134.

31. van Thor MCJ, Ten Klooster L, Snijder RJ, Mager JJ, Post MC. Long-term real world clinical outcomes of macitentan therapy in chronic thromboembolic pulmonary hypertension. Respir Med 2020; 167: 105966.

32. McLaughlin VV, Jansa P, Nielsen-Kudsk JE, Halank M, Simonneau $\mathrm{G}$, Grünig E, et al. Riociguat in patients with chronic thromboembolic pulmonary hypertension: Results from an early access study. BMC Pulm Med 2017; 17: 216.

33. Halank M, Hoeper MM, Ghofrani HA, Meyer FJ, Stähler G, Behr J, et al. Riociguat for pulmonary arterial hypertension and chronic thromboembolic pulmonary hypertension: Results from a Phase II long-term extension study. Respir Med 2017; 128: $50-56$.

34. Abman SH. Role of endothelin receptor antagonists in the treatment of pulmonary arterial hypertension. Аnпи Rev Med 2009; 60: $13-23$.

35. O'Callaghan DS, Savale L, Yaïci A, Natali D, Jaïs X, Parent F, et al. Endothelin receptor antagonists for the treatment of pulmonary arterial hypertension. Expert Opin Pharmacother 2011; 12: $1585-1596$.

36. Actelion. A study to evaluate efficacy and safety of macitentan $75 \mathrm{mg}$ in inoperable or persistent/recurrent chronic thromboembolic pulmonary hypertension (MACiTEPH). https://clinicaltrials. gov/ct2/show/NCT04271475 (accessed November 24, 2020). 